\title{
Suárez de Figueroa ante Tasso: del plagio ocultado a la devoción declarada
}

\author{
Ángeles ARCE MENÉNDEZ \\ Universidad Complutense de Madrid $^{1}$ \\ arcea@filol.ucm.es
}

Recibido: 11/06/2012

Aceptado: 29/06/2012

\section{RESUMEN}

El artículo examina la relación literaria existente entre Cristóbal Suárez de Figueroa y Torquato Tasso a lo largo de veinte años, en los que aparece el recuerdo del italiano en seis obras del español. Se analizan las distintas actitudes ante esta presencia: desde el plagio más desconcertante al más sentido homenaje, reflejado en la recreación -ya que no se puede hablar de una traducción al uso- del bautismo y muerte de Clorinda después del enfrentamiento con Tancredi, episodio en el que el erotismo tassiano queda matizado y se deja influir por la visión más recatada de un contrarreformista que tuvo que defenderse en Nápoles del tribunal de la Inquisición.

Palabras clave: Torquato Tasso, Cristóbal Suárez de Figueroa, Gerusalemme liberata, Clorinda y Tancredi, Contrarreforma.

\section{Suarez de Figueroa's attitude to Tasso: from concealed plagiary to declared devotion}

\begin{abstract}
The article examines the literary relationship existing between Cristóbal Suárez de Figueroa and Torquato Tasso over a twenty-year period, in which the Italian is remembered in six of the Spaniard's works. An analysis is made of the different attitudes shown in this presence: ranging from the most barefaced plagiary to the most heartfelt homage, reflected in the recreation, since we cannot call it a run-of-the-mill translation, of the christening and death of Clorinda after her confrontation with Tancredi. In this episode, the Tassian eroticism is muted and he allows himself to be influenced by the most modest view of a counterreformation figure who had to defend himself before the Inquisition in Naples.
\end{abstract}

Keywords: Torquato Tasso, Cristóbal Suárez de Figueroa, Gerusalemme liberata, Clorinda and Tancredi, Counterreformation.

\footnotetext{
${ }^{1}$ Departamento de Filología Italiana. Facultad de Filología (Edificio D). Universidad Complutense. Madrid 28040. 
Es de todos conocida la enorme influencia que la figura y la obra épica y pastoril de Torquato Tasso ejercieron en el mundo literario europeo y, muy especialmente, en nuestra península. Sin embargo, no deja de sorprender un hecho aparentemente contradictorio: mientras en las letras hispanas la presencia de Tasso puede rastrearse desde época muy temprana, la crítica española no se ocupó de él hasta mucho más tarde; en efecto, será en el siglo XVIII cuando empiece a ser citado con cierta asiduidad -e Ignacio de Luzán y su Poética pueden servir de ejemplo- pero, sobre todo, se le tiene en cuenta en el XIX, ya en pleno Romanticismo ${ }^{2}$. Lo cierto es que nuestros escritores de la Contrarreforma se fijaron en la atormentada personalidad del poeta napolitano dejándose impresionar por el Tasso personaje y su original concepción del poema épico cristiano, hasta el punto de que, ya en pleno Siglo de Oro, pasó a ser considerado como un modelo supremo, digno de imitación. Entre esos escritores áureos ocupa un lugar destacado Cristóbal Suárez de Figueroa (¿Valladolid 1571 - Roma o Nápoles 1644? $)^{3}$, autor controvertido y, hasta hace no mucho tiempo, uno de los más inmerecidamente olvidados por la crítica que se ocupa del siglo XVII español ${ }^{4}$.

Suárez de Figueroa -como le gustó llamarse a partir de 1603, después del fallecimiento de su padre, que ostentaba simplemente el apellido familiar de Suárezpasó más de la mitad de su vida en Italia en dos diferentes etapas: la primera, en el norte, de 1588 a 1604 -cuando obtuvo el Doctorado in utroque iure y ejerció algunos cargos relacionados con asuntos civiles del ejército español en el Milanesado-y la segunda, entre finales de 1622 hasta 1644, aproximadamente. Fue entonces cuando desempeñó diversos puestos de responsabilidad en el ámbito jurídico en el reino de Nápoles a las órdenes del Duque de Alba y del Virrey, viéndose injustamente implicado en el enfrentamiento cruzado entre las autoridades civiles y religiosas que le ocasionaron graves problemas con la Inquisición napolitana (Arce 1983: 29-68). Esta larga estancia de más de tres décadas en el país que el español consideró su "segunda patria" -e, incluso, casi la "primera", después de ciertos problemas que tuvo con algunos contemporáneos a causa de su difícil carácter- podría justificar el número de escritores italianos que aparecen recordados, traducidos o "utilizados" digamos que con discutible legalidad en muchos de los casos- en su producción literaria no demasiado extensa, si la comparamos con lo prolíficos que eran otros connacionales del momento. Pero de todos los nombres italianos, alguno práctica-

${ }^{2}$ En un artículo anónimo publicado en el Diario de Barcelona (2-V-1832) se citan juntos, por ejemplo, a Dante, Ariosto y Tasso como maestros de la "nueva" escuela romántica. Para muchos datos sobre Tasso y la literatura española remito al ya clásico libro de Joaquín Arce (1973) que abrió el camino a muchas investigaciones posteriores.

${ }^{3}$ Los datos biográficos sobre el autor están reunidos en la voz «Suárez de Figueroa, Cristóbal» del $D B E$ (Arce, en prensa) donde se resumen, además, las últimas investigaciones no ajenas a la controversia: quizás la más "impactante" de todas sea la que lo considera el autor del Quijote apócrifo, tradicionalmente atribuido a Avellaneda (Suárez Figaredo 2008).

${ }^{4}$ Esta afirmación era innegable cuando abordé el estudio de la biobibliografía figueroniana en mi Tesis Doctoral, defendida en un ya lejano 1978 (Arce 1983). Por fortuna, a partir de ese momento, la situación ha cambiado considerablemente, pudiendo consultarse la última bibliografía sobre Figueroa en Arce (en prensa). 
mente contemporáneo que, de una u otra manera, se recuerdan en sus textos -Dante, Petrarca, Boccaccio, Sannazaro, Ariosto, Tansillo, Garzoni, Guarini, ... ${ }^{5}-$ el de Torquato Tasso es el que aparece un mayor número de veces, nada menos que en seis de sus nueve obras de temática muy variada.

A continuación se señalarán las citas, de muy distinta índole e importancia, atendiendo a la fecha de publicación de la obra donde estas menciones aparecen entre 1609 y 1629 y en cuyas portadas ya consta el apellido completo de Suárez de Figueroa, apellido que él siguió utilizando pese a las críticas mordaces de muchos contemporáneos y que es con el que hoy lo conocemos. El amplio arco cronológico de esos veinte años servirá también para ver la evolución y la madurez literaria de Figueroa ante ese admirado modelo: utiliza el plagio para el Tasso pastoril en su primera obra, y se esmerará en la recreación de un episodio del Tasso épico en la última ${ }^{6}$.

1.- A los pocos años de su llegada desde Italia a la corte española, Figueroa recibe el encargo de escribir una novela pastoril en honor de la amada de su entonces mecenas. El español no puede negarse a la encomienda y en apenas dos meses tuvo que sacar a la luz su primera obra ${ }^{7}$ con el título de La constante Amarilis (Valencia, 1609). Entre la premura de tiempo y que para la temática bucólica no se sentía preparado - «tan niño y torpe me hallaba en aquel género de escribir» como confiesa en el Alivio segundo de El pasajero (Suárez de Figueroa 1617: 87)-, no encontró mejor solución que la que nos explica años después en esa obra, la más personal y, sin duda, una de las que mejor retratan la sociedad contemporánea. Deseando encontrar «en tan largo y difícil camino algún atajo» (Suárez de Figueroa 1617: 87) para elaborar las prosas y versos necesarios para su encargo, recurre a consejos poco ortodoxos ${ }^{8}$, al tiempo que confiesa lo que él mismo ha hecho en alguna ocasión:

\footnotetext{
${ }^{5}$ Con el título de «La literatura italiana en la obra de Cristóbal Suárez de Figueroa» se recoge todo un capítulo en mi monografía (Arce 1983: 667-783).

${ }^{6} \mathrm{Si}$ bien para la realización de este trabajo se han utilizado las primeras ediciones de las obras de Suárez de Figueroa y esas son las que se reseñan en la bibliografía final -téngase en cuenta que solo dos tienen ediciones modernas y anotadas- las páginas que constan en las respectivas citas proceden de ediciones digitalizadas, indicadas al final de cada entrada y llevadas a cabo, casi en su totalidad, por Enrique Suárez Figaredo. A pesar de que el criterio adoptado en esas ediciones no es rigurosamente filológico, ya que no se trata de facsímiles, se ha pensado que ese formato facilitaría la consulta a quienes no puedan acceder a los textos antiguos. Para la Gerusalemme liberata se sigue a Tasso (ed. 1991).

${ }^{7}$ Años antes en Italia había publicado como Cristóbal Suárez El pastor fido (Nápoles, Tarquinio Longo, 1602) pero se trataba de la traducción de la obra homónima de Giambattista Guarini (Venecia 1590).

${ }^{8}$ Consejos de este tipo le da el Doctor a un joven que desea escribir un libro: «Al corto caudal de propias poesías podéis aplicar el suplemento de las ajenas. Con que os hallaréis en estremo aliviado. El daño consistiera solo en que vuestro libro fuera como información de letrado: nada propio, todo ajeno; mas habiendo mucho de casa ¿qué importa pedir al vecino algo prestado para lucir en semejante fiesta?» (Suárez de Figueroa 1617: 82).
} 
Ponderé convenía, para subir presto a parte alta, si no se permitía dilación para labrar una sola escalera, enlazar unas con otras hasta la cantidad necesaria. Este símil fue puerto de mi borrasca, fue norte de mi navegación. Volaba desde allí adelante, mas era prestándome algunos sus alas. Cuanto a lo primero, entablé a mi placer los versos que tenía represados, que no eran pocos. Hacíales la cama con ciertas prositas ocasionadas; y tantos granos junté, que vine a perficionar el deseado montón. Apenas nacido [el libro], le repudié con ira, tratándole como adulterino. [Mientras que a la dama] sin haberla visto ni comunicado, le di título de hermosísima, de sumamente discreta y a maravilla constante (Alivio II, pp. 87- 88).

¿Creía, acaso, Figueroa que esta confesión justificaba su comportamiento, es decir, le permitía construir su novela con múltiples "retales" de otros escritores"? Por otro lado, si consideramos esos recuerdos como "lugares comunes" a los que acudían, casi sin excepción, todos los escritores del género, ¿podría ser tan criticable su actitud? Centrándonos en Tasso, que es de lo que se encarga este artículo, ¿por qué se habla de «desconcertante plagio» ya desde el título de un trabajo que se encarga de estudiar la técnica empleada por el español en su novela? (J. Arce 1972-73). Lo realmente "desconcertante" -al margen de que nuestros criterios y planteamientos estéticos con respecto al plagio hayan variado con el tiempo- se halla en el hecho de que la dependencia no es del Aminta tassiano, como cabría esperar, sino que la utilización "descarada" se hace a través de la primera traducción castellana de la favola boschereccia hecha por Juan de Jáuregui (Roma, Estevan Paulino, 1607). Aun reconociendo que el resultado poético en su conjunto no es malo, la única "originalidad" de Figueroa radica en que prosifica "hábilmente" los versos ya traducidos y, eso sí, "disfrazando" el resultado al insertarlos en diferentes lugares y sin señalar la procedencia. En efecto, en esta ocasión, ni el nombre de Tasso, ni el de Jáuregui ni el de sus respectivas obras van a citarse, ni de forma implícita ni explícita, en el texto ni en los paratextos iniciales, si bien no está claro que el vallisoletano quisiera ocultar esas fuentes ya que son «precisamente los mejores, los más conocidos episodios del Aminta los que pasan a la narración pastoril» (J. Arce 1972-73: 5) ${ }^{10}$.

\footnotetext{
${ }^{9}$ Recuerdos de Sannazaro o Guarini -además de Tasso-, entre los italianos, y de Montemayor o Carrillo de Sotomayor -además de Jáuregui- entre los españoles, se encuentran constantemente aunque utilizados de diferente manera (Arce 1983: 291-307).

${ }^{10}$ Como no se puede añadir nada nuevo a lo expuesto en el artículo mencionado, se reproduce, simplemente como muestra del "parecido", el conocido episodio de la abeja (J. Arce 1972-73: 24-25): 
2.- Pocos años después Figueroa escribe el poema épico España defendida (Madrid, Juan de la Cuesta, 1612), en el que, como en otras obras similares del género, se va a seguir el modelo de la Gerusalemme tanto en el sintagma del título (Arce 1983: 390-392) como en la métrica, reconociendo ya desde el Prólogo de la primera edición, la dependencia y devoción por «el Taso ${ }^{11}$, Príncipe de la poesía heroica» (Suárez de Figueroa 1612: s/p). Sin embargo, esta humilde confesión se matiza, aunque no desaparece pese a la evidente reducción, en una posterior edición de la obra (Nápoles, Egidio Longo, 1644) ${ }^{12}$. Véanse los dos paratextos:

\section{Jáuregui}

Entonces me encendió nuevo deseo / De arrimar a los suyos estos labios; / Y con mayor astucia y más aviso / Que nunca había tenido (¡mira cuánto / El amor sutiliza nuestro ingenio!) / Se me ofreció un engaño con que en breve / Llegar pudiese a conseguir mi intento; / Y fue desta manera: que fingiendo / Me había picado una furiosa abeja / El labio bajo, comencé a dolerme / De suerte que el remedio que la lengua / No demandaba, el rostro le pedía. / La simplecilla Silvia, / Piadosa de mi mal, se ofreció luego / Con el remedio a la engañosa herida, / Y hizo jay triste! Mucho más crecida / Y más mortal mi herida verdadera, / Cuando llegó sus labios a los míos. (Aminta, vv. 505-522)

${ }^{11}$ Figueroa escribe siempre «Taso», como era habitual entre los contemporáneos. Lope, en La dama boba por ejemplo, lo hace rimar con Garcilaso (III, $1^{\mathrm{a}}$ ). Por otro lado, Figueroa conserva la costumbre italiana de acompañar el apellido con el artículo, costumbre que si bien era "consentida" en la época, no debería de haber sido tan repetida por críticos españoles, incluso "ilustres", en épocas más cercanas a nosotros.

${ }^{12}$ El único ejemplar de esta edición de la Española defendida -que, sin duda por "error involuntario" se presenta en la portada como «quinta impressión»- lo he localizado en la BNE y, bajo las cifras 44 de la fecha, parcialmente tachada, parece leerse un 36. La ausencia de otros ejemplares en las numerosas bibliotecas italianas y españolas que he podido rastrear hacen me impiden confirmar con seguridad la validez de la fecha, aunque yo me sigo inclinando más por aceptar la de 1644 . 


\section{Prólogo de 1612}

A éste pues [Tasso], insigne en los requisitos apuntados, imité en esta obra, y con tanto rigor en parte de la traza, y en dos o tres lugares de la batalla entre Orlando y Bernardo, que casi se puede llamar versión de la de Tancredo y Argante: supuesto me valí hasta de sus mismas comparaciones (téngase en cuenta con esto, no imagine el censor se pretende encubrir, o pasar de falso, este que él llamará hurto) y ojalá tuviera yo talento para trasladarle todo en nuestra lengua, con la misma elegancia y énfasi, que suena en la suya (p. 9)
Prólogo de 1644

[Tasso es] en su idioma Príncipe de los números épicos. A éste, pues, en los requisitos apuntados, inventé en parte de la invención deste argumento, llevado de la costumbre común en que los últimos autores de fábricas semejantes, siempre estamparon las huellas de los primeros (p.27)

Ya en el interior del poema español, dividido en catorce Libros -y no Cantos como el modelo-, vemos que los elementos "recordados" son más, muchos más, de los «dos o tres» mencionados y anticipados por el autor en los preliminares de la primera edición. De las decenas de ejemplos que no procede señalar en este momento $^{13}$, se reproducen únicamente dos para mostrar que esa dependencia va más allá de recordar el modelo épico que representaba el poema de Tasso, al que en España se le reconoció, casi de inmediato, el valor hermenéutico de un texto clásico. El primer ejemplo se refiere al traslado de la conocidísima onomatopeya del conciliábulo infernal, presidido por Plutón, en un episodio similar al de la Liberata, en el que no falta en el segundo endecasílabo de la octava española la supresión de la preposición $a$ con el objeto directo animado:

Chiama gli abitator de l'ombre eterne

Il rauco suon de la tartarea tromba

(Gerusalemme, IV, 3)
Ya el ronco son de la tartárea trompa ${ }^{14}$

Llama los tenebrosos moradores

(España defendida, Libro III, 2, p. 84)

donde los horrores, los monstruos, los terribles sonidos... inundan «las Plutóneas salas [...] de la tremenda Dite» (Suárez de Figueroa 1612: Libro III, oct. 6, p. 85).

En el otro caso, aprovechando la semejanza entre ambas lenguas, Figueroa no tiene inconveniente en reproducir, dentro de la misma octava, idéntica rima consonante a la de Tasso en los versos 1, 3 y 5 e, incluso, palabra-rima en el último verso: «intenta / presenta / violenta», dice el español (Libro XIV, oct. 52, p. 395) donde Tasso había utilizado «ritenta / appresenta / violenta» (XIX, 14).

${ }^{13}$ Los paralelismos entre el poema italiano y el español pueden verse en Arce (1983: 714-727).

${ }^{14}$ En otro poema de corte tassiano publicado con anterioridad a la España defendida, y que Figueroa podía haber conocido, se repite idéntico recurso retórico y rítmico «El ronco son de la tartárea trompa, / congrega en gran rumor sombras eternas» (Cristóbal de Mesa, Las Navas de Tolosa, Madrid, 1594). En la literatura española se repite este verso, como se recoge en J. Arce (1973: 75-76). ya que en la Poética de Luzán se utiliza como ejemplo de onomatopeya (Luzán 1789: 357). 
Por último, permítaseme una última reflexión: ¿podría, acaso, considerarse también como homenaje al poeta renacentista que la España defendida tuviera una nueva impresión corregida y aumentada (Nápoles, Egidio Longo) en 1644, año en el que se conmemoraba en la ciudad partenopea, donde el vallisoletano residía, el primer centenario del nacimiento de Tasso ${ }^{15}$.

3.- Lo que encontramos en la obra siguiente, Plaza universal de todas ciencias y artes (Madrid 1615), es una situación diferente ya que, desde la portada se afirma «Parte traduzida del Toscano y parte compuesta» y aunque, de nuevo, lo afirmado por nuestro Figueroa no sea del todo cierto, oficialmente se trata, como es sabido, de la traducción de la Piazza universale di tutte le professioni del mondo de Tommaso Garzoni (1549-1589), publicada por primera vez en Venecia en 1584 (Arce 1983: 471-542 y Arce 2008).

En esta obra, dividida en discursos como el original, aparece el nombre del poeta sorrentino en seis ocasiones aunque en cinco de los casos se trata de la mera inclusión rutinaria de su nombre en una lista más o menos amplia entre otros "ilustres" citados dentro de una determinada profesión o actividad de las centenares que se enumeran en esa magna obra enciclopédica de Garzoni, auténtico best seller del Renacimiento. En la versión española se menciona, como se ha dicho, a Tasso seis veces, como vamos a ver a continuación: en la primera se le incluye simplemente como participante de una academia:

Son tanto más nobles estos Académicos, cuanto más ilustres por sangre, por loable vida, y por insignes ciencias, hallándose ricos y copiosos de valor; como en su tiempo lo fueron el Bembo, el Ariosto, el Molza [en realidad una mujer, Tarquina Molza], el Varqui [Benedetto Varchi], el Trisino, el Taso, el Pico, el Cintio [Giovan Battista Giraldi, conocido como Cinzio], y otros modernos sin número, que ilustran sus Academias, no sólo con dichos, sino con raras obras que dejaron impresas (Suárez de Figueroa 1615: 165-166) ${ }^{16}$.

En los dos casos siguientes ya no se trata de tener presentes las dos obras maestras del italiano -Aminta y Gerusalemme- sino que se recuerdan dos de sus Dialoghi más conocidos entre los veintiocho escritos entre 1579 y 1586 durante la reclusión del poeta en el hospital de Sant'Anna: en el primer caso, el discurso 66 (69 en Garzoni) dedicado a los «Jugadores» comienza con una definición «El juego, a quien difine Torcato Taso como una contienda de fortuna entre dos o más» ( $\mathrm{p}$. $524)^{17}$, mientras que en el otro caso, dedicado a los «Embajadores» (disc. 81, 83 del

${ }^{15}$ En mi monografía sobre Figueroa se dedica un largo capítulo al estudio de la Española defendida (Arce 1983: 341-422) y se recogen, por primera vez, las octavas que diferencian las dos versiones figueronianas (Arce 1983: 845-871).

${ }^{16}$ Aunque los discursos en ambos textos se señalan en números romanos, aquí los indicaré en arábigos por motivos prácticos. La cita se corresponde con el disc. 14, de los pocos que en la obra española mantienen la numeración de Garzoni.

${ }^{17}$ Está aludiendo, sin mencionar el título, al Romeo overo del giuoco, reelaborado después en el título definitivo de Il Gonzaga secondo overo del giuoco, diálogo dedicado «Al molto magnifico signor 
italiano) se aconseja, a modo de "bibliografía", que «quien quisiera ver con más extensión algo desta materia, lea el Mensajero de Torcuato Taso, que discurre por excelencia» (p. 607) donde se hacía el retrato ideal del perfecto embajador, sinónimo de mensajero ${ }^{18}$. En el cuarto ejemplo, el sorrentino aparece mencionado junto a Guarini, Picolomini, Pino, Dolce, Trissino y otros, entre los «modernos» autores de comedias (discurso 91, p. 656, correspondiente al 103 de la Piazza) y, por último, en quinto lugar y refiriéndose a los poetas que escribieron «en verso heroico», se incluyen entre clásicos como Virgilio u Homero a «los dos Tassos, padre y hijo» (discurso 105, p. 722, equivalente al 154 del italiano).

La sexta mención de la Plaza universal quizás sea la cita más significativa ya que hay una toma de conciencia por parte del español; en el discurso 46 (48 de la Piazza), dedicado a «los traductores, profesores de lengua e intérpretes», después de traducir -o resumir como hace la mayor parte de las veces a lo largo de su obra- lo dicho por Garzoni, Figueroa añade, en uno de los pocos fragmentos originales de su versión, una crítica a las malas traducciones de autores "universales" que existen en castellano:

Así por este descuido (no sé si diga incapacidad) sacaron a luz traducciones tan flojas por una parte, y por otra tan duras, que es imposible dejarlas de poner debajo los pies, con particular menoscabo de sus dueños. Testigos desta verdad pueden ser los desfigurados Ariosto, Tasso y Virgilio, que con ser dechados de erudición y elegancia, y por eso tan queridos de todos, los desconocemos, y abominamos por la mala interpretación que se hizo dellos (p. 435).

Si nos atenemos a las fechas -ya que, aunque la Plaza se publica en 1615, por los preliminares sabemos que ya estaba terminada en $1612-$, con respecto a las traducciones de la Gerusalemme la crítica del vallisoletano podría referirse únicamente a las llevadas a cabo por Juan Sedeño y a la manuscrita de Bartolomé Cairasco de Figueroa ${ }^{19}$. Si en la queja, además, entrase en juego el Aminta, habría que pensar en la primera traducción realizada por Jáuregui (Roma, Estevan Paulino, 1607) que Figueroa tan bien conocía como se pone de manifiesto en La constante Amarilis, ya que la segunda versión del sevillano, aparecida bajo el título de Rimas (Sevilla, Francisco de Lyra y Varreto 1618), quedaría descartada por las fechas.

Después de estas seis "apariciones" de Torquato dentro del texto de la versión española de Garzoni, vale la pena comentar un hecho curioso: entre los doce sonetos laudatorios en italiano que se incluyen en los preliminares de la Piazza, hay uno del propio Tasso, que Suárez de Figueroa no va a reproducir en su trabajo. Sin em-

\footnotetext{
Alessandro Pocaterra», cortesano de la casa estense a quien Tasso dirigió numerosas cartas; es un diálogo «nel quale si discorre del giuoco, operazione che tanto più artificiosamente si fa quanto meno a l'arbitrio della fortuna soggiace» (Tasso ed. 1958: 451-497; 451).

${ }^{18}$ Se refiere, en efecto, al diálogo titulado Il Messaggiero, dedicado «Al Serenissimo signor Vincenzo Gonzaga, Principe di Mantova e di Monferrato» (Tasso 1958: 249-332).

${ }^{19}$ Puede tratarse de la Ierulasem libertada de Sedeño de 1587 o, más improbable, de la versión inédita y llena de italianismos del Gofredo famoso de Cairasco, muerto en 1610, que Figueroa no tiene en cuenta en sus distintas adaptaciones de la Gerusalemme.
} 
bargo, esto podría ser fácilmente explicable: el español critica duramente la práctica de incorporar poesías laudatorias, habitual entre los escritores de la época tanto italianos como españoles, y nunca utilizará esta práctica en sus propias obras. La explicación que da el Doctor, personaje identificado con el propio Figueroa en el Alivio segundo de El pasajero, no puede ser más clara:

¿También vos pretendéis incurrir en el vicio de soneticos mendigados? Ligereza notable, absurdo terrible. [...] Si la obra es mala, millones de sonetos en su alabanza no la hacen buena; y, al contrario, si está bien escrita, no ha menester para adquirir aplauso, ajenos puntales. Bestial estratagema, ridícula presunción querer el idiota, el incapaz, conseguir nombre de discreto, de docto, con un centenar de bernardinas que pega en el frontispicio de alguna obrilla del todo indocta, insulsa y lega (Suárez de Figueroa 1617: 83; Alivio II).

4.- La cita anterior nos sirve para introducir un nuevo título, El Pasajero. Advertencias utilissimas a la vida humana (Madrid 1617), sin duda el trabajo más conocido del vallisoletano y que marcará un antes y un después dentro de su producción literaria, ya que esta obra, junto con las dos siguientes, serán sus trabajos más originales. A lo largo de los diez Alivios en los que se divide el libro, se respira ambiente italiano; y no solo porque el viaje emprendido por los cuatro "pasajeros", que dialogan entre sí sobre los asuntos más variados, tiene lugar a lo largo de toda la península italiana, sino porque vamos a encontrar varias referencias a los autores más universales de ese país ${ }^{20}$. Sin embargo, pese a esta gran presencia literaria italiana el nombre de Tasso solo aparece, de forma explícita, una única vez en toda la obra: al criticar a quienes utilizan la autoalabanza, el Doctor hace referencia a alguien que se vanagloriaba de no necesitar fuentes:

Publicó cierto conocido un librete de unas otavas devotas, y tratando algunas veces conmigo de su excelencia y cultura, le colocaba en las esferas. De ningún modo quería admitir por compañeros a Virgilio y Taso, antes afirmaba hacía su poema a los de entrambos conocidas ventajas en todo. Hallábame yo confuso sin atreverme a desengañarle con aspereza, respeto de no importarme cosa semejante frenesí. Con esto quedaba el amigo contentísimo, imaginando sentía yo lo mismo, que él temerariamente publicaba de sí (Suárez de Figueroa 1617: 366, Alivio IX).

Palabras que, de alguna manera, nos permiten introducir la siguiente reflexión con respecto a la imitación o al tan "denostado" plagio. Como ese tema ya ha sido tratado en el primer apartado al hablar sobre La constante Amarilis, solo me resta completar lo allí dicho ya que esas consideraciones sobre poética, materia de la que se ocupa fundamentalmente el Alivio II, se hacen dentro de El pasajero. En efecto,

\footnotetext{
${ }^{20}$ Me limito a enumerar esos nombres que aparecen en El pasajero: se hace una traducción parcial de un soneto de Marino (Alivio VI); de Boccaccio se recuerdan algunos nombres de personajes y obras (Alivios II y $V$ ) y se elabora en el VII -además de introducirlo en el propio relato- un cuento del Decameron (II, 5); por último, de los otros "grandes", Dante es citado dos veces (Alivios II y IX) y tres Petrarca (Alivios II, $V$ y $I X)$.
} 
vuelve a ser el Doctor, personaje a quien toda la crítica identifica con el autor, quien opina sobre el tema y parece querer justificar la apropiación, no demasiado "legal", que él hizo de numerosas fuentes ${ }^{21}$-metáforas que esconden sintagmas del tipo «alas ajenas» $\mathrm{o}$ «escaleras enlazadas entre sí»»- al verse obligado a cantar la hermosura de una amada «a maravilla constante» a la que ni siquiera conocía ${ }^{22}$.

5.- Estando en la corte española a punto de emprender viaje nuevamente a Italia, da Figueroa a la imprenta un nuevo libro, Varias noticias importantes a la humana comunicación (Madrid, Tomás Iunti, 1621, aunque ya terminado un año antes), dividido esta vez en veinte Variedades. Libro de tono didáctico, de densa y reflexiva prosa que, al no utilizar la forma dialogada, resulta de lectura especialmente monótona porque le falta la crítica irónica con la que Figueroa solía arremeter contra sus contemporáneos cuando era blanco de los ataques que muchos le lanzaban en el Madrid áureo. El estilo erudito y la sintaxis complicada acompañan la disertación sobre los temas más variados que podrían tener interés para la sociedad, añadiendo a las discusiones citas de auctoritates que le daban más solvencia. Y en un caso concreto, y a pesar de que el vallisoletano no fuera especialmente un defensor del género femenino, intertextualiza y parafrasea una cita tassiana, la única de todo el libro, para salir en defensa de la mujer casada:

Gárrula y falaz llamó a la hembra el Taso, esto es, engañosa y charlante; mas perdone poeta tan culto: muchas hay que pueden servir de excepción a su regla. Déjase entender por sí cuánto en la mujer importe el silencio. Virtud grande es en ella el hablar poco (pienso pretendo en general inaudito imposible) con quien no fuere su marido, salvo en las ocurrencias domésticas con los criados (Suárez de Figueroa 1621: 397, Variedad 17)

alusión que el poeta italiano había utilizado en un contexto diferente al referirse en su poema a la «falsa Armida» ${ }^{23}$ con estos endecasílabos:

${ }^{21}$ Sin embargo, quien parece defender el plagio e incluso no tiene inconveniente en vanagloriarse de haberlo utilizado, es capaz, también, de decir estas palabras: "Cuanto al robo [de textos ajenos], ningún alguacil os hará causa por él. A la pobreza de ingenio disculpa la remisión; [...] Tengo por fruslería la nota de descarado. Es campo espaciosísimo el de la murmuración. [...] Todos cuantos escriben en todo género de facultades son cornejas vestidas de ajenas plumas. Publícase la obra; vanse los ojos a lo menos bueno, y murmúralo la lengua. Son otros linces de aprovechamientos; que así se llaman hoy los hurtos. Pasan algunos días, y, al cabo, el preso se da por libre; olvídase todo, y, por lo menos, el autor engorda con las maldiciones y dineros que sacó del trabajo» (Suárez de Figueroa 1617: 82).

${ }^{22}$ Casi las mismas palabras las repite Figueroa en la octava 106 de la España defendida (Madrid 1612), en boca de un pastor cuya «lira compitió con la estrangera» para decir: «Celebré con el nombre de Constante / del vago Manzanares en la orilla, / aquella dulce amada, y tierna amante, / de belleza y aviso maravilla» (Libro II, vv. 1-4, p. 82).

${ }^{23}$ Armida representa en el poema la imagen del mal, de la seducción y del engaño, identificándose siempre con lo femenino ya que más que maga, Tasso la presenta como la mujer de la que se enamora Rinaldo (Sempoux 1958). 
Femina è cosa garrula e fallace;

vuole e disvuole; è folle uom che sen fida. (Gerusalemme, XIX, oct. 84).

6.- Y llegamos al sexto y último libro que en este trabajo merecerá más atención que los anteriores. Después de unos años asentado en Nápoles, escribe Suárez de Figueroa la que será su última obra original, también de tipo misceláneo, publicada en esa ciudad en 1629. La acción tiene lugar en Posílipo ${ }^{24}$, a las afueras de la ciudad partenopea, cuyo nombre aparecerá en el título: Pusilipo. Ratos de conversación en los que dura el passeo (Nápoles 1629), hermoso lugar en el que los cuatro personajes que intervienen en el diálogo se reúnen para dar sus opiniones sobre temas heterogéneos ${ }^{25}$-de ahí que se adopte el nombre de Juntas para los seis apartados que conforman la obra (Arce 1983: 622-666).

Los años no han pasado inútilmente y el español, con casi sesenta años y sin estar a las órdenes de ningún mecenas, se nos presenta como un escritor maduro que no necesita plagiar ni utilizar "a escondidas" temas de otros. Muy por el contrario, lo que hace con Torquato Tasso -por no mencionar lo que también se percibe en otras reminiscencias de Italia o menciones literarias ${ }^{26}$ - puede considerarse como un confesado homenaje y reconocimiento de afecto y devoción en las cinco ocasiones en las que se tiene presente el recuerdo del poeta renacentista: a) la asociación de Sorrento con uno de sus hijos más ilustres; b) la simple mención de su nombre ligada a la defensa de la imitación; y c) tres recuerdos extraídos de la Gerusalemme: la utilización de dos breves pasajes con la traducción de los versos respectivos y, por último, la recreación de un episodio del canto XII, sin duda, el más universalmente conocido del poema italiano al que voy a referirme con más detenimiento un poco más adelante.

En el primer caso, la ubicación geográfica en la que se encuentran al comienzo de la «Quarta Iunta» los cuatro protagonistas de la obra da pie al recuerdo de quien allí nació; y se habla de Tasso en un largo fragmento en el que intervienen todos los

${ }^{24}$ El nombre italiano es Posillipo, pequeña colina entre el golfo de Nápoles y Pozzuoli, que era famosa por albergar los restos de Virgilio y Sannazaro.

${ }^{25}$ Se nota que Figueroa quería estar a bien con el Virrey, a quien dedica la obra y, al mismo tiempo, el tono religioso y casi místico que se respira en muchos de los temas sobre religión, política o filosofía natural demuestra que quería limar asperezas con el poder eclesiástico, que ya empezaba a tenerlo en su punto de mira.

${ }^{26}$ Además de describir la ciudad y sus alrededores antes de comenzar la primera junta (Suárez de Figueroa 1621: 13-15; $1^{\mathrm{a}}$ Junta, pp. 13-15), se hace una historia del reino de Nápoles ( $5^{\mathrm{a}}$, p. 172) y la crítica a la delincuencia napolitana $\left(2^{\mathrm{a}}\right.$, p. 68); se recuerda, entre otros, a Petrarca $\left(2^{\mathrm{a}}\right.$, p. 97 y $3^{\mathrm{a}}$, p. 120), a Dante ( $5^{\mathrm{a}}, \mathrm{p}$. 187) y al Pastor fido y su traducción, cita que reproduzco porque hace referencia, sin mencionarlo, a la defensa de su propio trabajo frente a críticas que pudo recibir al coincidir con el cambio de apellidos. En efecto, del poema de Guarini hizo Figueroa, a falta de una, dos traducciones distintas, una bajo el nombre de Cristóbal Suárez (Nápoles 1602) -que gozó a su vez de otra edición en la misma ciudad en 1622- y otra con su nombre completo (Valencia 1609): «pues como dice el Fido (no sé si con alguna felicidad vuelto en nuestro romance, por no faltar quien como ignorante y mordaz, sin entenderlo, y lo que es más, apenas habiéndolo visto, a bulto lo condene)» $\left(5^{\mathrm{a}}, 186\right)$. 
personajes dando cada uno su propia opinión pero coincidiendo en el tenor de la alabanza más absoluta ${ }^{27}$ :

[LAUREANO]: ¿En qué estábades tan atento, y con la imaginación tan ocupada, poco antes que los tres llegásemos, que apenas de vos fuimos vistos? Sin duda, merece ser sabida la causa del arrobo, pues era fuerza fuese bien digna.

FLORINDO: Contemplaba en Surrento, patria felicísima del gran Torcato, y con gran afecto la veneraba interiormente, como madre de tan insigne Varón de ingenio tan esclarecido.

ROSARDO: Bien fundado estaba el éxtasis en honra de quien engendró tan resplandeciente lumbre de facundia y sutileza. Parece adelantó en aquel género, cuanto pudo la locución, subiendo al mismo paso de punto el conceto; unión dificilísima, ya que suele perder el uno sus quilates, con la exornación de la otra. Mas aquel portento de la Poesía, unió con tan elegante destreza uno y otro, que casi cierra los pasos a los más altos futuros ingenios para la competencia de tan dichosos, y bien colocados realces.

SILVERIO: Por esta razón, no es posible enriquecer con tantos tesoros suyos otras lenguas; tan lejos se halla de poder ser con propiedad y valentía traducido, aunque heredase el intérprete el mismo ardor de sus ideas, transformándose del todo en sus tropos y concetos.

LAUREANO: ¿Habrá quien lo haya intentado, no obstante todas esas dificultades, que habéis propuesto?

SILVERIO: Y muchos; empero todos infelizmente ${ }^{28}$ : porque, según referí, es casi para todos, por su concisión, inaccesible, habiéndole de volver a la letra: lo que quizás fuera más fácil parafraseándole $\left(4^{\mathrm{a}}\right.$, p. 124).

En segundo lugar, se cita al poeta sorrentino en un párrafo en el que Rosardo defiende la imitación de los "grandes maestros"29; esta será, pues, no solo admitida, sino incluso aconsejada entre los que se consideran cultos:

Todos estos maestrazos se deben imitar con toda diligencia; siendo entre todos más dichosamente culto, quien más le bebiere el espíritu [...]. La primera clase de los mayores ingenios se fueron imitando unos a otros: Virgilio a Homero y a Teócrito; a Virgilio el Taso; y así los demás ( $\left.4^{\mathrm{a}}, \mathrm{p} .147\right)$.

\footnotetext{
${ }^{27}$ La presentación de los cuatro - «ingeniosos sujetos, si diferentes en profesión, en afecto y voluntad virtuosamente conformes»)- que se hace antes de la primera Junta sirve para entender la postura de sus intervenciones: Rosardo «anciano... y dedicado a las letras políticas», que la crítica identifica con el autor -como el Doctor de El pasajero- y llevará la voz cantante en las discusiones; Florindo de «robusta edad [ejercía] en la milicia»; Silverio «expertísimo en la cautelosa filosofía de Palacio» y Laureano «Académico de algún nombre en el napolitano Liceo» (pp. 14-15), aunque no siempre sea él quien introduzca temas literarios.

${ }^{28}$ Nueva alusión a las no buenas traducciones castellanas existentes sobre las obras tassianas (véase nota 19 ).

${ }^{29}$ En otro lugar y defendiendo a Góngora, el mismo Rosardo añade: «solo la emulación es lícita; [...] siendo permitida, por fundarse en virtuosa competencia» $\left(6^{\mathrm{a}}\right.$, p. 191).
} 
Y, por último, los tres casos que se mostrarán a continuación se corresponden con un conocimiento directo de la Liberata por parte del vallisoletano: dos utilizaciones textuales y la conversión de varias estancias del canto XII en un romance.

El primer ejemplo se encuentra en el mismo Prólogo del Pusílipo ya que Figueroa utiliza, señalando canto y octava, los versos correspondientes a la conocida comparación del «niño enfermo» (l'egro fanciul). El español capta perfectamente el sentido moral y educativo que Tasso había otorgado a esos endecasílabos, que se remontaban a una sentencia clásica ${ }^{30}$, y los pone-traducidos y adaptados en cuatro octosílabos- precisamente, como lema de su obra:

\section{Gerusalemme}

Così a l'egro fanciul porgiamo aspersi di soavi licor gli orli del vaso: succhi amari ingannato intanto ei beve, e da l'inganno suo, vita riceve

\section{Pusílipo}

Assí al niño enfermo offrecen dulce la orla del vaso, y a un tiempo lo amargo bebe, dándole vida su engaño.

Del Taso, Canto 1, Otava 3

Y después de la sentencia -que será un tema recurrente en la literatura española posterior $^{31}$ - comienza el texto del Prólogo en el que se anticipa al lector el contenido veladamente moralizante que encontrará en sus páginas:

Esto puntualmente pasa en el título deste libro. Dél se podrá colegir, no haya dentro cosa de sustancia, y entenderlo así, sería manifiesto engaño. Ardid y estratagema fue para alentar desganados, como se suele con manjar delicado y atractivo. Propone consejos sabios y exquisitos pareceres [...], obliga con la dulzura de las palabras y recrea con el deleite de las sentencias, que como flores van por su campo esparcidas (p. 10).

\footnotetext{
${ }^{30}$ Es decir, los absinthia taetra de Lucrecio (De Rerum Natura, I, 936-942).

${ }^{31}$ Posiblemente haya sido Ignacio de Luzán -como en el anterior ejemplo mencionado sobre la onomatopeya en la nota 14- quien contribuyó a la difusión de la sentencia: «La Poesía, uniendo el de[le]yte al provecho, ha logrado hacer sabroso lo saludable: al modo que al enfermo niño se suele endulzar el borde del vaso, para que así engañado beba sin hastío ni repugnancia qualquier medicamento por amargo que sea» (Luzán 1789: 76, cap. X del Libro I). Cuando Jovellanos utiliza la sentencia en una carta a Carlos González de Posada (verano de 1805) cita directamente al italiano para dar su opinión de cómo deberían hacerse las "censuras" para que resultasen más provechosas para el censurado. Aunque no he podido ver directamente el manuscrito del ilustrado asturiano, me resisto a pensar que se encuentren en él tantos errores y "horrores" ortográficos como se transcriben en el texto de la BAE, del que señalo solo el primero de los cuatro verso de la cita, como más espectacular e injustificable; dice "teóricamente" Jovellanos: «[...] debemos a nuestros prójimos cierta delicadeza en los consejos; [...] pues si los dirigimos a su bien, debemos endulzarlos [...] pues ya dijo el Tasso: "Così allegro fanciul porgiamo aspersa [sic]"» (Jovellanos 1859: 226), donde el niño "enfermo", l'egro del italiano se convierte en "alegre" y el adjetivo de final de verso no concuerda en género y número con el sustantivo al que acompaña (orli).
} 
Es evidente que Figueroa, como Tasso, tuvo presente el famoso tópico literario del delectare et prodesse, pensando en el carácter bivalente de "entretener y enseñar" que toda obra literaria debía tener ${ }^{32}$.

En el siguiente caso nos encontramos con una inserción textual puesta en boca de Laureano, uno de los dos jóvenes interlocutores, que tiene el papel de defensor de la poesía; para describir a una joven y hermosa muchacha dice:

Blancura, y carmín de salud, y pocos años, en rostro, y mejillas; contenta con la pureza, y simplicidad de la naturaleza; de quién se podía decir como de la otra el famoso Taso: Sus negligencias son los artificios (Suárez de Figueroa 1629: 10).

que traduce literalmente el último endecasílabo de una octava que hacía referencia a la belleza virginal de Sofronia: «le negligenze sue sono artifici» (Gerusalemme, II, $18)^{33}$. La aparición de Sofronia puede servirnos de nexo para introducir en el tercer y último ejemplo a la otra heroína tassiana a la que Figueroa va a dedicar su romance; nexo casual, por supuesto, ya que el español no podía imaginar que tres siglos después un crítico hubiera encontrado «misteriose affinità» entre Sofronia y Clorinda, es decir, entre los cantos II y XII que Tasso dedica respectivamente a las dos mujeres (Giampieri 1995: 62-68).

Tras estas citas que ejemplifican distintas etapas de la recepción del poeta sorrentino por parte de Figueroa, procede analizar, como meta final de este recorrido, el tercer y último ejemplo del Pusílipo derivado de la Gerusalemme, que merece una atención especial: se trata de la versión transformada que Figueroa hace del episodio de la muerte de Clorinda en manos de Tancredi. Comienza la «Quarta Iunta» del Pusílipo alabando la figura del «gran Torcato» (p. 162) -que es, además, «insigne varón de ingenio tan esclarecido», «portento de la poesía», etc. $\left(4^{\mathrm{a}}, \mathrm{p}\right.$. 124) - y se comenta la dificultad que deben ofrecer sus obras ante las pésimas traducciones existentes en castellano. Todo esto ya ha sido comentado, pero a continuación Silverio, aunque no experto en materia literaria, dice que, pese a las evidentes dificultades métricas y estilísticas que ofrece el texto original, él se ha atrevido a intentarlo:

No ha mucho, que leyendo una tarde cierto episodio trágico suyo, a saber, la muerte de Clorinda que por error le dio Tancredo, hallándome enternecido del caso, pues en efeto mueve lo lastimoso, procuré traerlo a nuestra lengua, no con ligaduras de consonantes, sino con la asonancia que suele ser común con los romances castellanos $\left(4^{\mathrm{a}}\right.$, p. 124).

${ }^{32}$ En un tenor similar se había manifestado Figueroa en Varias noticias, obra también de temas educativos: «Como la medicina, que por accidente trata la enfermedad, para evitándola poder entretener mejor la salud [...] Al título deste libro querría, pues, se debiese la elección y hábito de lo bueno, el conocimiento y exclusión de lo malo» (Suárez de Figueroa 1629: 31).

${ }^{33} \mathrm{Se}$ trata de Sofronia, la heroína cristiana serena y valiente, cuyos rasgos de coraje y racionalidad la hacen mostrarse con una cierta frialdad hacia los sentimientos de otros personajes; Tasso hace hincapié insistentemente en su superioridad moral y en su virginidad, pese a las virtudes seductoras que le otorgaron la naturaleza y el amor. 
Y de esta manera se introduce el romance, uno de los doce que forman parte de las setenta y seis composiciones poéticas que se intercalan dentro de la exposición en prosa del Pusilipo ${ }^{34}$.

Lo mismo que va a ocurrir en el romancero español basado en Ariosto $^{35}$ en el que los autores, ante la amplitud temática del poema italiano parecían fijarse en una sola historia para después desarrollarla, también aquí Figueroa se centra en una breve escena -aunque sumamente significativa de la Liberata- y, en boca de Silverio, presenta minuciosamente el momento de la muerte de Clorinda. Está claro que el tema de la conversión de la muchacha "infiel" -más allá de que todo el canto XII o, incluso, el episodio del famoso combate sean muy importantes dentro del marco general del poema italiano- será esa conversión, repito, lo que atrajo la atención de Figueroa; y eso no solo por sus propias convicciones religiosas o porque era un tema habitual en la literatura caballeresca, sino porque no se puede olvidar que el vallisoletano estaba en pleno proceso de enfrentamiento con las autoridades religiosas napolitanas $\mathrm{y}$, aunque el problema fuese motivado por haber cumplido estrictas órdenes de sus superiores civiles, el hecho no impidió que el español sufriera cárcel e, incluso, fuera excomulgado por el Santo Oficio. Todos estos factores pueden explicar, a priori, el interés con el que en el romance se trata el tema de la conversión y bautismo, como si con ello el autor tuviera la esperanza de verse libre de la acusación de herejía que lo acechaba o, al menos, pudiera servir para paliar la ira del Santo Tribunal.

Entendida, pues, esa posible justificación, vemos que el "adaptador" supo enmarcar el emotivo y trágico relato dentro del contexto del canto XII donde, a pesar de una evidente "condensación", no van a faltar los elementos clave de todo el episodio: desde la alusión a la noche, marco de la acción (Gerusalemme, XII, oct. 1), a la desesperación y el dolor de Tancredi que quiere ser enterrado dentro de la tumba de su amada (XII, 99).

Al elegir a Clorinda vemos un motivo más que une a Figueroa con su modelo: el reconocimiento del protagonismo femenino ${ }^{36}$. A lo largo de los veinte cantos de la Gerusalemme, nos damos cuenta del enorme relieve que Tasso otorga a la figura de la mujer que, sin alejarse de los estereotipos de los poemas caballerescos -la guerrera ${ }^{37}$, la maga, la enamorada o la virgen- se muestra con gran sensibilidad y autonomía. Figueroa se percató de ello ya que tiene presente en varias de las citas de Tasso ya mencionadas a tres de las cuatro mujeres del poema: a Sofronia, Armida pero, sobre

${ }^{34}$ Para facilitar el análisis y ver al completo los dos textos, se reproducen en Apéndice los versos de Figueroa (4a Junta, pp. 124-126) y las siete octavas del episodio de Tasso (1991, canto XII, octs. 64-70).

${ }^{35}$ Recuérdese que en muchas imitaciones españolas derivadas de Ariosto y Tasso se utiliza junto con la octava, el metro corto de octosílabos, considerado más nacional (Chevalier 1968).

${ }^{36}$ Dice al respecto Michele Prisco: «Se l'Orlando è il poema virile per eccellenza della nostra letteratura, la Gerusalemme tassesca è poema squisitamente e dolentemente femminile» (Prisco1978: 282).

${ }^{37}$ El tema de la virgo bellatrix o 'mujer guerrera' es otro de los tópicos de la literatura caballeresca que en el teatro áureo español se completa con el de la mujer disfrazada de varón. 
todo, a la pagana Clorinda, personaje paradójico y la auténtica protagonista del canto XII, que conserva en la versión española el mismo nombre ligado a chlorós 'pálido', ya que, milagrosamente, había nacido blanca de padres etíopes aunque cristianos ${ }^{38}$. De todo el canto, conocido también como "el canto de Clorinda"39, el español eligió precisamente las estrofas -de la 64 a la 70 - dedicadas al desenlace final del duelo entre los dos guerreros de distinta religión cuando, ya mortalmente herida, la infiel implora el bautismo a su enemigo cristiano (Giampieri 1995).

Desde un punto de vista métrico observamos que las siete octavas, es decir, los cincuenta y seis endecasílabos que trataban el episodio, se transforman en sesenta y ocho octosílabos asonantados, estructurados en cuartetas, metro más ligado a la tradición española que facilitaba el acercamiento a la difícil poesía de Tasso. Es el propio Silverio, después de "recitada" en voz alta la composición a sus compañeros, el que justifica la asonancia ya que hacerlo de otra manera hubiera sido «no solo difícil, sino imposible, volviéndose con el rigor de consonantes» $\left(4^{\mathrm{a}}, \text { p. } 126\right)^{40}$.

Con el cambio de estructura métrica y la consiguiente reducción de los espacios rítmicos silábicos -que se convierten en 544 frente a los 616 del texto italiano-, Figueroa utiliza también como Tasso encabalgamientos para prolongar las ocho sílabas del verso, que se ve forzado, al mismo tiempo, a una ruptura rítmica en el interior del siguiente ${ }^{41}$.

Para hacer un análisis objetivo del trabajo realizado por Suárez de Figueroa lo primero que no debemos olvidar es que nos encontramos con una "recreación" literaria y no con una traducción propiamente dicha, a pesar de que en las palabras con las que se presentaba el romance se decía, con cierta ambigüedad, «procuré traerlo [el episodio] a nuestra lengua» $\left(4^{\mathrm{a}}, \mathrm{p} .124\right)$. El caso es que el vallisoletano va a alternar-según lo exijan bien el momento o bien necesidades rítmicas- distintos métodos: seguir bastante de cerca el texto original, alterar el orden de los elementos narrativos o, incluso, resumir en unos pocos versos iniciales, las trece octavas anteriores que describían el combate. Véase en el cuadro siguiente la correspondencia de versos:

${ }^{38}$ Como es conocido, Clorinda es la versión cristiana de la griega Clariclea de Heliodoro.

${ }^{39}$ El canto XII es circular con respecto a Clorinda, ya que toda su paradójica historia se recoge en él: comienza con un largo flash-back donde el fiel criado Arsete cuenta el nacimiento cristiano de la joven (octavas 20-40), se habla de su militancia pagana meramente accidental y concluye con su muerte cristiana (Perelli 1991).

${ }^{40}$ Una defensa similar del metro corto frente a la octava se encuentra en otro poema que imita a Tasso, el Fernando o Sevilla restaurada (Milano, Henrico Estefano, 1632) de Juan Antonio de Vera y Figueroa, que utiliza la redondilla y lo justifica así en el prólogo: «Hízome elegir este género de rima creer que en versos mayores obligados a consonantes, estancia por estancia, no es el Taso poeta que pueda ser traducido bien, ni medianamente; y lo principal porque estimo las coplas castellanas capaces de cantar toda obra heroica». En cualquier caso, la sustitución de las octavas por la forma del romance, considerado metro más español, era habitual, como ya se ha dicho, en ciertas imitaciones de Tasso y Ariosto (Chevalier 1968).

${ }^{41}$ Los versos 13-16 o 29-32 del romance pueden servir de ejemplo. Téngase también en cuenta que la crítica suele coincidir en considerar sumamente compleja la estructura de la octava tassiana, precisamente por el encabalgamiento y el verso bimembre (Cataneo 1978). 


\begin{tabular}{|c|c|c|}
\hline TASSO (endecasílabos) & FIGUEROA & No de octosílabos \\
\hline [Octavas 51-63] & vv. $1-6$ & 6 \\
\hline Octava 64 & vv. $7-8$ & 2 \\
\hline Octava 65 & vv. 9-10 & \multirow{2}{*}{$2+6=8$} \\
\hline Octava 66 & vv. $19-24$ & \multirow{2}{*}{$8+4=12$} \\
\cline { 2 - 3 } & vv. $11-18$ & \\
\hline Octava 67 & vv. $25-28$ & 12 \\
\hline Octava 68 & vv. $29-40$ & 12 \\
\hline Octava 69 & vv. $41-52$ & 8 \\
\hline Octava 70 & vv.53-60 & 8 \\
\hline
\end{tabular}

Tabla 1. Bloques narrativos

En líneas generales se puede observar que el español se va a extender en la interpretación de la parte central del romance mientras será más parco en palabras, y al mismo tiempo más original, al comienzo y al final de la composición.

Antes de comenzar a analizar el paralelismo entre ambos textos siguiendo bloques narrativos o estróficos, quisiera hacer una observación previa de carácter general. Los versos de Tasso, al formar parte de un contexto más amplio, no necesitan mencionar los nombres de los protagonistas que intervienen en el duelo -salvo de pasada a Clorinda en la oct. 64- porque eran perfectamente conocidos por el lector. Sin embargo, se va a aludir constantemente a ellos en las octavas posteriores mediante pronombres de tercera persona, bien en sus formas sujeto o formas complemento. Además de las dieciséis formas pronominales que se refieren exclusivamente a la pareja, Tasso habla también de «il cavaliero» (oct. 69, v. 6) y de «la bella donna» (oct. 69, v. 8$)^{42}$.

En la versión española, por el contrario, sí era necesario y pertinente mencionar al comienzo el nombre de los protagonistas y así se hace en el v. 2 hispanizando, incluso, el «Tancredo». Por otro lado, Figueroa no va a recurrir a tantos referentes como el original -hecho que ocasiona, a veces, cierta ambigüedad ${ }^{43}-\mathrm{y}$, cuando lo hace, sustituye las formas pronominales más puntuales y cortas del italiano, por un sintagma nominal que le ocupaba gran parte del octosílabo, restándole espacio para incorporar otros elementos: a «Tancredo» lo denomina como «el infausto» (v. 7), «el contrario» (27), «el semivivo» (31), «el caballero» (58) y «el triste» (61); Clo-

\footnotetext{
${ }^{42}$ Para las citas del texto italiano (Tasso 1991) señalo primero el número de la octava y después el verso. Como formas sujeto -además de las dos de primera persona introducidas en el estilo directo de Clorinda (66,1 y 68,8) - el resto son de tercera: egli $(64,3 ; 65,1 ; 67,3$ y 68,5$)$, ella $(64,7$ y 65,3$)$ y colei $(68,6)$; como formas átonas de complemento tenemos: gli $(66,7 ; 66,8$ y 69, 7), le $(64,8$ y 65, 7) o la $(65,8$ y 67, 7); y como formas con preposición: a lei $(65,5)$ e in lei $(69,3)$.

${ }^{43}$ Véase como ejemplo estos dos octosílabos: «al pronunciar las palabras / de su salud instrumento» (vv. 49-50) donde no hubiera estado de más aclarar que es él el que pronuncia las palabras y que la salud se refiere a la de ella.
} 
rinda es «la guerrera» (9), «la bella» (51) y «la Fénix de hermosura» $(39)^{44}$. Por otro lado, no hay en la traducción ningún pronombre-sujeto de tercera persona y sí se utiliza el ambiguo le indirecto dos veces para el masculino (vv. 11 y 35 ) y una para el femenino (v. 22).

Pasemos ahora al análisis de los textos por bloques narrativos:

1.- Las dos cuartetas iniciales o, para ser más exactos, los seis primeros octosílabos del romance tienen que ponernos en antecedentes de lo que se va a narrar, mostrando el español, en este caso, no solo originalidad sino una magnífica capacidad de síntesis ya que esos versos no van a corresponderse con los de la primera estrofa italiana, como cabría esperar. Con el «fiero combate» (v.1) y el «desangrados los dos» (v. 5) se resumen nada menos que las trece octavas, plagadas de alusiones eróticas (de la 51 a la 63), del encarnizado combate cuerpo a cuerpo entablado entre dos guerreros enemigos que no se reconocen no solo por la oscuridad nocturna que los rodea, sino porque, además, Clorinda ha cambiado su armadura por otra que no tiene dibujado el tigre que la identifica en el campo de batalla.

En esos pocos versos iniciales, sin duda los más personales de la versión española, a Figueroa le da tiempo a situar la acción durante la noche al aire libre con un hermoso paralelismo (vv. 3 y 4) y a señalar anafóricamente, casi con un quiasmo, las condiciones extremas en las que se encuentran los combatientes: "ya desangrados los dos / ya los dos faltos de aliento» (vv. 5 y 6). Con la fugaz presencia de «la noche» (v. 3), se hace mención al sintagma «era la notte» ${ }^{45}$, con el que había comenzado el canto XII y con el que Tasso había querido anticipar, al margen de la alusión horaria, el episodio tenebroso y terrible que iba a tener lugar más adelante.

2.- Después de un feroz enfrentamiento, el segundo que ambos tienen en el poema, llega el episodio de la estancia 64 donde la joven es mortalmente herida -cuando su «ora fatale è giunta» $(64$, v. 1). Los dos combatientes están exhaustos, pero mientras al caballero cristiano no parecen flaquearle las fuerzas al hundir su espada en el cuerpo de su oponente (64, vv. 3-6), la agredida que «già sente / morirsi» se desploma (64, vv. 78). Clorinda ya no tiene nada de guerrera ni de la apariencia masculina que se ocultaba tras la vieja armadura que se había enfundado para despistar al enemigo y que será el desencadenante del dramático equívoco. Queda al descubierto un alma femenina y sensible, aunque todavía no identificada, que en trance de muerte ofrece a su enemigo la mano en señal de perdón y solicitud de ayuda.

\footnotetext{
${ }^{44}$ Fénix tiene el valor de «lo que es singular, exquisito o único en su especie» (Diccionario de Autoridades).

${ }^{45}$ Tasso utiliza el sintagma «era la notte» cuatro veces en el poema (II, 96; VI, 103; VIII, 16 y XII, 1) siguiendo el topos virgiliano nox erat que encontramos varias veces en la Eneida (por ej. IV, 522528 y VII, 26-30) y será recogido por la tradición caballeresca. La forma tuvo un enorme eco en el Romanticismo español aunque, a partir de Espronceda, muchas veces se trivializa; el popular comienzo «Era de noche y, sin embargo, llovía», utilizado por primera vez por el periodista gallego Antonio Neira de Mosquera, se convirtió en un dicho proverbial. Sobre el valor del nocturno en Tasso, véase Noero (1964).
} 
En pocos lugares de la Liberata se percibe, como en esta octava 64, una tan clara diferencia de sexos: él posee la fálica espada - «il ferro ... di punta» $(64$, v. 3$)-$ y con furia homicida la empuja y la introduce en un joven cuerpo de formas femeninas como deja intuir el vocabulario que utiliza el poeta italiano. La coraza ya no existe, misteriosamente ha desaparecido; se nos habla, por el contrario, de un «bel sen» escondido tras una sutil túnica bordada en oro $(64$, v. 5) -ropaje, en efecto, no demasiado apropiado para alguien que iba a combatir- que deja imaginar, con contornos esfumados y sugerentes, «le mammelle» manchadas con la cálida sangre que brota de la herida reciente $(64$, v. 7). Sin embargo, y pese a la importancia del momento, el hermoso lenguaje empleado por Tasso no debió parecerle demasiado oportuno al siempre "prudente" Figueroa -obsesionado como pocos por la presión contrarreformista-, y trató de "moralizar" y "suavizar" la fresca y espontánea sensualidad tassiana, si bien en la Gerusalemme no se llega a alcanzar el regodeo sensual y la trepidación de la turbación amorosa que se deja sentir en el Aminta. Ante una estrofa de tal intensidad y belleza, el español en dos octosílabos se limita a decir, con una lapidaria brevedad, propia del controlado erotismo manierista:

con una punta el infausto

penetra el amado pecho (vv. 7-8).

Tengamos en cuenta, además, que al tratar de "dulcificar" el sustantivo "pecho» con el adjetivo «amado»-que seguramente le parecía un sintagma de resultado menos sensual o atrevido-, Figueroa, de forma consciente quizás, aunque no podemos saberlo con seguridad, estaba desvirtuando el sentido del fragmento original porque tenía que saber perfectamente que "su" Tancredo no podía referirse con cariño a su oponente ya que no se "descubrirá" hasta mucho más adelante concretamente en el v. 36-, que ese "enemigo" herido escondía a su amada Clorinda, similar a la «fronte / non conosciuta ancor» de la octava 67 del italiano.

A partir de esos ocho octosílabos más originales, la versión española se hará más literal, si bien se va a ver alterado el orden de las dos octavas siguientes -primero se introducirá la 66 y después la 65- cuando se anticipan las palabras de perdón de la moribunda.

3.- Los cuatro endecasílabos de la octava 66 que recogían la petición de bautismo de la joven pagana -aún desconocida, insisto, para su adversario que ni siquiera le reconoce la voz bajo el yelmo- muestran las sólidas convicciones religiosas de Tasso (66, vv. 1-4). Figueroa inmediatamente se fija en ellas y procura reproducirlas casi al pie de la letra aunque no guarden el mismo orden en el traslado. Así, los ocho versos (vv. 11-18) que el romance dedica a la intervención de Clorinda se abren, precisamente, con la forma «dice» (v. 11) que introduce el estilo directo con la voz «flebile e soave» $(66$, v. 6) de la moribunda. Con una puntual simetría, en el texto español:

$1^{\circ}$ ) se reproduce el apóstrofe «amigo» (v. 12) para hacer más cercano el perdón que se repite en su forma verbal y sustantiva (66, vv. 1 y 13), un perdón para el alma ya que el cuerpo de Clorinda no lo necesita; 
$\left.2^{\circ}\right)$ aparece el pronombre sujeto de primera persona, propio del estilo directo: «Yo te perdono» (v. 13) como el «io ti perdon» (66, v. 1);

$3^{\circ}$ ) encontramos los versos fragmentados (vv. 13-15 frente a 66, vv. 1-3) y el doble encabalgamiento (vv. 13-14 y vv. 14-15, como 66, vv. 1-2 y 3-4);

$\left.4^{\circ}\right)$ se hace una correcta interpretación del latinismo paventare $(66$, v. 2) como «temer» (v. 15) y

$5^{\circ}$ ) no falta, incluso, la locución «un no sé qué de suave» (v. 25) que tienen las palabras de la muchacha, que enternecen el corazón del guerrero enemigo. La fórmula, que se hizo muy popular, reproduce la expresión similar de «un non so che di... soave» $(66$, v. 6$)$ típica del estilo esfumado de Tasso ${ }^{46}$.

4.- La antítesis, figura que junto con el paralelismo es considerada también propia del estilo tassiano, es constante en todo el canto XII -hombre / mujer, amor / odio, virilidad / espíritu femenino...- pero esa antítesis se muestra de manera especial en la estrofa 65 en relación con el espíritu religioso: mujer pagana / hombre cristiano; vida del alma / muerte del cuerpo; situación trágica / salvación eterna. Figueroa no pasa por alto ninguno de esos elementos, teniendo en cuenta que está ante alguien que suplica el bautismo, y conserva, además, los términos de la que fue «rebelde» (v. 19) en vida, por ser infiel, y quiere ser «sierva» (v. 20) de Dios en la muerte - «se rubella / in vita fu, la vuole in morte ancella» (65, vv. 7-8)- idea que Tasso conserva octavas más adelante del mismo canto cuando sigue considerando a Clorinda como «una fanciulla a Dio rubella» (87, v. 4).

El verso de ritmo ternario con el que Tasso aunaba las virtudes teologales «spirto di fé, di carità, di speme» $(65$, v. 6$)$ no tiene cabida dentro de un verso de arte menor y Figueroa tiene que adaptar los espacios rítmicos: traslada las cuatro largas sílabas de la palabra «Esperanza» al verso 23 y añade, para completar el siguiente octosílabo, el bisílabo «zelo» (v. 24), otra virtud muy apreciada por el español mientras ejercía como jurista en Italia. Si el español tiene mucho cuidado con el aspecto religioso, no lo percibimos tanto en lo poético ya que sigue hablando de «la guerrera» (v. 9) cuando Tasso matizaba en sus palabras que la heroína belicosa ha desaparecido para dejar paso a una pobre mujer acosada por un amenazante varón: «segue egli la vittoria, e la trafitta / vergine minacciando incalza e preme» $(65, \mathrm{vv} .1-2)$.

5. - Tancredi, aunque está exhausto por el combate, no puede negarse como cristiano a la dramática petición del sacramento bautismal y se dirige a un «picciol rio» $(67$, v. 2) para coger el agua salvadora. Y es entonces, al retirar el yelmo del de hasta entonces anónimo adversario, cuando descubre, horrorizado, la identidad de su amada. En esta parte central del romance -como lo hará con la estrofa anterior y posterior a esta- Figueroa utiliza doce octosílabos (vv. 29-40) para trasladar una octava, la 67; en este caso, no solo no necesita resumir palabras, sino que la ampli-

${ }^{46}$ La locución, que se irá lexicalizando con el tiempo, se hizo muy popular tanto en la literatura española como en la italiana perdurando hasta la estética prerromántica. En La constante Amarilis Figueroa había utilizado la misma expresión dos veces en el Discurso II: «un no sé qué de no entendida afición» (Suárez de Figueroa 1609: 86-87) y «un no sé qué de amargo» (pp. 109-110). 
ficatio -96 espacios rítmicos frente a los 88 de Tasso- le permite, incluso, ser más explícito que el italiano:

$1^{\circ}$ ) respeta el imperfecto durativo del verbo «scaturia / corría» (67, vv. 2 y 29 , respectivamente) acompañado del gerundio «mormorando» / «murmurando» (67, vv. 2 y 30 );

$\left.2^{\circ}\right)$ sustituye la pequeñez del adjetivo tassiano «picciol rio» $(67$, v. 2$)$ por el diminutivo «arroyuelo» (v. 30), que ayudaba a mantener el mismo número de sílabas del sintagma original;

$\left.3^{\circ}\right)$ cambia la forma breve del pronombre sujeto «egli» $(67$, v. 3$)$ por el sustantivo «semivivo» (v. 31) -más acorde, por cierto, con la situación real del combatiente $-\mathrm{y}$

$4^{\circ}$ ) en ambos casos, después de utilizar el yelmo como recipiente para transportar el agua (67, vv. 3 y 32), al caballero le tiembla la mano (67, v. 5) «al descubrir lo cubierto» (v. 36), utilizando el español una antítesis típica del lenguaje barroco.

Para intensificar el dolor del momento Figueroa repite tres veces, una de ellas a distancia, la forma verbal «vio» (vv. 37, 39 y 40), y aunque no consigue su belleza trata de emular a Tasso que había empleado la doble repetición del pronombre femenino directo junto a las dos formas verbales «la vide, la conobbe» $(67$, v. 7$)$, reforzadas en el verso siguiente que cerraba la estrofa con dos exclamaciones y dos sustantivos del campo semántico de los versos anteriores: la «vista» remite a «vide» y la «conoscenza» a «conobbe» (64, vv. 7-8). Lamentablemente, el español se limita a introducir un octosílabo entre exclamaciones, «joh miserable portento!» (v. 38), que resulta algo prosaico si lo comparamos con la belleza y perfección estilísticas utilizadas por Tasso.

6.- La siguiente octava vuelve a ser trasladada en tres cuartetas (vv. 41-52), pero no habrá ya traducción literal como en la anterior: Tancredi, agotado por la lucha y abatido por el dolor - «non morì già» $(68, v .1)$-, reúne fuerzas de flaqueza para pronunciar, como improvisado e involuntario ministro «i sacri detti» del rito bautismal que proporcionarán, en una curiosa paradoja, la vida eterna «a chi col ferro uccise» $(68, \text { v. } 4)^{47}$; en el español se hace hincapié en el abatimiento que muestra el guerrero que «al ver la infeliz tragedia / de dolor muriera luego» (vv. 43-44) y solo es capaz de reponerse para decir «las palabras», sin ningún adjetivo, (v. 49) restando, incomprensiblemente, solemnidad al momento ya que el adjetivo "sacro» queda desplazado al v. 42. Esta aparente falta de parafernalia en el momento de impartir el sacramento es más sorprendente si tenemos en cuenta que en otra de sus obras, aunque en un contexto y situación diferentes, el español había dedicado un largo pasaje a la conversión de otro infiel: el indio Caupolicán ${ }^{48}$. Es como si el contrarreformista

${ }^{47}$ Es sabido que el enamoramiento entre guerreros de distinta religión estaba en la tradición caballeresca y, más concretamente, puede verse el paralelismo con el boiardesco amor entre Ruggiero y Bradamante.

${ }^{48}$ En los Hechos de don García Hurtado de Mendoza (Madrid, Imprenta Real, 1613), y tras la detención del jefe Caupolicán, «cierto religioso... deseó tratar de su salvación» hasta que el indígena «satisfecho de algunas dudas... por la plática de la fe, declaró quería morir cristiano... tomando el 
Figueroa se hubiera percatado de que el mismo Tasso había restado cierta relevancia a la forma de enfrentarse ante un sacramento tan importante: en la ceremonia no hay sacerdote ni testigos, tiene lugar en plena noche y la conversión "secreta" no gozará de la propaganda que tanto gustaba a la Iglesia católica (Giampieri 1995: 142-148).

Ya bautizada, el agradecimiento de la nueva cristiana es idéntico en ambos autores, una tenue sonrisa: aunque un lacónico verbo en pasado del italiano -«colei ... rise» $(68, v .6)-$ se convierte en un más explícito «la bella / mostró semblante risueño» (vv. 51-52) aunque no reproduce tampoco las beatíficas palabras de la que «in atto di morir... / dir parea: "s'apre il cielo; io vado in pace"» $(68$, vv. $7-8)$, llenas de espíritu religioso.

7.- Seguidamente, con una cierta alteración del orden, Figueroa repite, aunque modificados, los mismos elementos que estaban en la estancia 69 de la Liberata: la doncella moribunda tiene los ojos fijos en el cielo «in lei converso» $(69$, v. 3$)$, es decir, preparado para recibirla (vv. 53-56) pero mientras omite la bella imagen cromática recogida en las flores - «gigli sarian miste viole» $(69$, v. 2$)$ - hace uso de una amplificatio que podría considerarse de tipo ornamental: enriquece con dos adjetivos «gli occhi» $(69$, v. 3$)$ en la típica languidez barroca de «fijos... / los eclipsados luceros» (vv. 53-54) e «il cielo» del italiano se convierte en «el sitio del gozo eterno» (v. 56), haciendo gala de un mayor éxtasis espiritual.

La extrema palidez del rostro de Clorinda es idéntica en ambas versiones: «bel pallore» $(69, \text { v. } 1)^{49}$ y «pálido hermoso» (v. 59); como Clorinda en su estado no puede pronunciar palabras, es su mano desarmada -«nuda e fredda» $(69$, v. 5$)$ en Tasso pero exenta de calificativos en Figueroa (v. 57) - la que se dirige hacia Tancredi en señal de paz y perdón; y finalmente, en ambos autores se identifica la muerte con la placidez del sueño (Tasso 69, v. 8 frente al v. 60 del vallisoletano) repitiendo el tópico clásico del somnus mortis imago que se remontaba a los clásicos y al Trionfo della Morte de Petrarca ${ }^{50}$. Una lacónica forma verbal, «passa» (69, v. 8) y «espira» (v. 60), señala el momento definitivo de la muerte.

8.- La estrofa 70, que se ha considerado la última del fragmento tassiano objeto del análisis, recoge el derrumbe físico y moral del cruzado a quien, tras fallarle las pocas fuerzas que había acumulado poco tiempo antes para poder cumplir con la

nombre de Pedro. [...] Solemnizose esta conversión grandemente entre los españoles» y no pudiendo impedir su ejecución "así feneció este varón [...] mostrando hasta en la muerte la magnanimidad que tuvo en vida» (Libro III, p. 102).

${ }^{49}$ Giampieri señala el paralelismo, y a la vez la diferencia, entre el «bel pallore» de Clorinda del canto XII, como consecuencia de la muerte, y el «bel volto... che non è pallidezza» de Sofronia (II, 26) que «indica l'assenza di paura» (Giampieri 1995: 65).

${ }^{50}$ El mismo tópico había sido utilizado por Figueroa en la «Junta Segunda» del Pusilipo: «[Al sueño] le llaman retrato de la muerte, pues en nada se diferencia de un difunto un dormido» (p. 52), mientras que en La constante Amarilis (Valencia 1609) lo que se identifica no es el sueño, sino la noche que «es retrato de la muerte» (Discurso Primero, p. 66). 
ceremonia religiosa (oct. 70, v. 2 frente a vv. 61-64), se desvanece de dolor. Está tan inmóvil en el suelo (v. 65) junto al cadáver de su amada - «in sé mal vivo, e morto in lei ch'è morta» ( 71, v. 8$)$ - que, al verlos, nadie distinguiría «cuál es el vivo o el muerto» (v. 68). Con este dramático octosílabo final, que recuerda «el semivivo» utilizado por Figueroa con anterioridad (v. 31), se pone de manifiesto el deteriorado aspecto que presenta Tancredi.

En los versos finales del romance -de la misma manera que se había hecho al comienzo para ponernos en antecedentes de lo que se nos iba a contar- Figueroa recoge alusiones diseminadas aquí y allá en otras octavas del canto XII para cerrar, así, el círculo del episodio narrado: expresiones del tipo «la bella anima sciolta al fin seguiva» $(71$, v. 3$)$ o «l'anima fugace» $(84$, v. 1$)$, etc., son recordadas en el «ausente ya el alma» (v. 61) de la joven muerta; con respecto a Tancredi las alusiones son más numerosas, no en vano su vida continúa pese a su desolación: «el triste..., rendido a su flaqueza y sentimiento..., inmoble... su aspecto...» (vv. 61-66), parecen tener presente «al cavalier giacente» $(74$, v. 2$)$ con un «tenebroso aspetto» $(80$, v. 3) que había hecho pensar a sus propios soldados que había fallecido (octs. 7174); incluso él mismo se sorprende cuando se recupera del desmayo y lamenta no estar muerto: «Io vivo? Io spiro ancora?» (v. 75). Es evidente que Tasso con su peculiar sicología hace hincapié en lo físico y en lo moral del caballero cristiano que se muestra abatido tanto por las heridas y el cansancio de la batalla, como por el dolor y el remordimiento al haber dado muerte, aunque de forma involuntaria, a la mujer que $a m a^{51}$.

Como resumen final podría decirse que nos encontramos con dos textos, productos de épocas diferentes - tardo Renacimiento manierista y Barroco- y, por tanto, de distinto gusto y sensibilidad. No hay que olvidar tampoco que traducir a Tasso no ha sido nunca tarea fácil, ya que estamos ante uno de los estilistas más refinados de la lírica europea del momento, y que posee, además, un gran dominio de los recursos rítmicos y expresivos. Frente a él, no se puede negar que Figueroa fue un crítico refinado, gran conocedor de la lengua italiana y entusiasta admirador de su literatura, que se esforzó en hacer en esta "recreación" del canto de Clorinda un más que discreto trabajo de adaptación, a pesar de transformar en el popular octosílabo del romance la elegante octava de la épica culta italiana -que, por cierto, el español supo utilizar con soltura y bastantes buenos resultados en la España defendidapero, pese a no haber conseguido repetir muchas de las hermosas imágenes de Tasso, a la versión española no le faltan belleza formal y dramatismo.

Creo por todo ello que, por encima de las valoraciones, en general excesivamente severas, sobre la actitud literaria de Cristóbal Suárez de Figueroa, no cabe ninguna duda de que con el romance incorporado a la prosa de su última obra original le está dedicando a Torquato Tasso un emocionado homenaje, reconociendo que este iba a ser uno de sus episodios más conocidos. Y quien sabe si en la elección del

\footnotetext{
${ }^{51} \mathrm{Al}$ respecto, no deja de ser significativo que estos versos de Tasso hayan sido utilizados por Sigmund Freud como ejemplo literario de "angustia neurótica" y en dos de sus trabajos hace expresa mención al remordimiento y al delirio enfermizo de Tancredi (Giampieri 1995: 80).
} 
tema pudo influir también el hecho de que por los años en que el español se trasladó a Italia, se estrenaba en el Carnaval de Venecia de 1624 una hermosa obra musical, a mitad de camino entre el madrigal y la ópera, del cremonés Claudio Monteverdi titulada Il combattimento di Tancredi e Clorinda ${ }^{52}$. En la escena, además de los dos protagonistas que luchaban bajo sus corazas, aparecía un tercer personaje, el Texto, que con su voz melodiosa de castrato o sopranista, introducía los versos de Tasso, un gran poeta renacentista cuya inquietante y compleja personalidad sicológica y literaria es la que, sin duda, sigue atrayendo la atención del lector moderno.

\section{REFERENCIAS BIBLIOGRÁFICAS ${ }^{53}$}

ARCE, Joaquín (1972-73): «Un desconcertante plagio en prosa de una traducción en verso», Filología Moderna 46-47, pp. 3-29.

ARCE, Joaquín (1973): Tasso y la poesía española, Barcelona, Planeta.

ARCE MENÉndEZ, Ángeles (1983): Cristóbal Suárez de Figueroa: nuevas perspectivas de su actividad literaria, Madrid, Editorial Complutense. $<$ http://eprints.ucm.es/9073/1/T9308.pdf $>$

ARCE MENÉndeZ, Ángeles (2008): «Suárez de Figueroa y su versión de la Piazza universale de Garzoni: entre texto y paratexto», Cuadernos de Filología Italiana 15, pp. 93-124.

ARCE MENÉNDEZ, Ángeles (en prensa): «Cristóbal Suárez de Figueroa» en J. Olmedo (ed.), Diccionario Biográfico Español (DBE), Madrid, Academia de la Historia.

CATANEO, Gualdo (1978): «Varietà e unità nella Gerusalemme liberata», en Carlo Ballerini (ed), Atti del Convegno di Nimega sul Tasso, Bologna, Patron, pp. 15-34.

CHEVAlier, Máxime (1968): Los temas ariostescos en el Romancero y la poesía española del Siglo de Oro, Madrid, Castalia.

Di BENEDETTO, Arnaldo (1992-93): «Un esempio di poesia tassiana: il canto XII della Gerusalemme Liberata», Studi Tassiani 40-41, pp. 233-248.

GIAMPIERI, Giampiero (1995): Il battesimo di Clorinda. Eros e religiosità in Torquato Tasso, Fucecchio, Edizioni Dell'Erba.

JoVELLANOS, Gaspar Melchor de (1859): Obras publicadas o inéditas de don G. M. de Jovellanos, Madrid, Rivadeneyra (BAE, 50).

LUZÁN, Ignacio de (1789): La Poética o Reglas de la poesía en general ... corregida y aumentada por su mismo Autor..., Madrid, Antonio Sancha.

NoERO, Carlo (1964-65): «Il notturno nella Gerusalemme Liberata», Studi Tassiani 14-15, pp. 35-39.

${ }^{52}$ La obra estrenada en el Palazzo Mocenigo de Venecia cuando Monteverdi (1567-1643) era Director de música en San Marcos, tuvo mucho éxito. Prueba de la actualidad del episodio y de la obra musical es que todavía se representó dentro de los Veranos de la Villa recientemente en Madrid (28-82011).

${ }^{53}$ No pretenden ser estas referencias, como es obvio, una "bibliografía exhaustiva" sobre Tasso o el argumento tratado. Se mencionan los trabajos utilizados para el desarrollo del tema 
Perelli, Antonella (1991): «La divina Clorinda», Studi Tassiani 39, pp. 45-76.

PIERANTOZZI, Decio (1984): «La Gerusalemme Liberata come poema religioso», Studi Tassiani 32, pp. 29-42.

PRISCO, Michele (1978): «I personaggi femminili nella Gerusalemme Liberata», en Carlo Ballerini (ed), Atti del Convegno di Nimega sul Tasso, Bologna, Patron, pp. 281-296.

SEMPROUX, ANDRÉ (1978): «Armida allo specchio», en Carlo Ballerini (ed), Atti del Convegno di Nimega sul Tasso, Bologna, Patron, pp. 307-329.

SozZI, Bortolo Tommaso (1954): «Il mondo spirituale e poetico del Tasso», Studi sul Tasso, Pisa, Nistri-Lischi, pp. 269-281.

SuÁreZ DE FIgUeroA, Cristóbal (1609): La constante Amarilis. Prosas y versos, Valencia: junto al Molino de Rovella. (El texto se cita a través de la tesis de María Asunción SATORRE GRAU: Estudio y edición de La constante Amarilis de Cristóbal Suárez de Figueroa, Madrid, Universidad Complutense 1995. $<$ http://eprints.ucm.es/tesis/19911996/H/3/AH3007202.pdf>

SuÁrez de FigueroA, Cristóbal (1612): España defendida. Poema heroico, Madrid, Juan de la Cuesta. <http://users.ipfw.edu/jehle/CERVANTE/othertxts/ Suarez_Figaredo_EspanaDefendida.pdf $>$

SUÁREZ DE FIGUEROA, Cristóbal (1615): Plaza universal de todas Ciencias y Artes, Madrid, Luis Sánchez. <http://users.ipfw.edu/jehle/CERVANTE/othertxts/ Suarez_Figaredo_PlazaUniversal.pdf $>$

SUÁREZ DE FIgUEROA, Cristóbal (1617): El Pasagero. Advertencias utilissimas a la vida humana, Madrid, Luis Sánchez. < http://users.ipfw.edu/jehle/CERVANTE/ othertxts/Suarez_Figaredo_El_Pasajero.pdf $>$

SUÁREZ DE FIGUEROA, Cristóbal (1621): Varias noticias importantes a la humana comunicación, Madrid, Tomás de Iunti. http://users.ipfw.edu/jehle/CERVANTE /othertxts/VariasNoticias.pdf>

SuÁreZ De FigueroA, Cristóbal (1629): Pusilipo. Ratos de conversación en los que dura el passeo, Nápoles, Lazaro Scoriggio. <http://users.ipfw.edu/jehle/ CERVANTES/othertxts/Pusilipo.pdf>

SuÁrez FigAredo, Enrique (2008): El Quijote apócrifo, Barcelona, Ed. Carena. También en <http://parnaseo.uv.es/Lemir/Revista/Revista10/SuarezFigaredo/ SuarezFigaredo.pdf $>$

TASSO, Torquato (1958): Dialoghi, ed. de Ezio Raimondi, Firenze, Sansoni editore.

TASSO, Torquato (1991): Gerusalemme Liberata, Giorgio Cerboni Baiardi, Ferrara, Cossimo Panini. 


\section{APÉNDICE}

\section{TORQUATO TASSO ${ }^{54}$}

Ma ecco omai l'ora fatale è giunta che ' 1 viver di Clorinda al suo fin deve. Spinge egli il ferro nel bel sen di punta, che vi s'immerge e 'l sangue avido beve; e la veste, che d'or vago trapunta le mammelle stringea tenera e leve, l'empie d'un caldo fiume. Ella già sente morirsi, e 'l piè le manca egro e languente.

Segue egli la vittoria, e la trafitta 65 vergine minacciando incalza e preme. Ella, mentre cadea, la voce afflitta movendo, disse le parole estreme; parole ch'a lei novo un spirto ditta, spirto di fé, di carità, di speme: virtù ch'or Dio le infonde, e se rubella in vita fu, la vuole in morte ancella.

-Amico, hai vinto: io ti perdón... perdona tu ancora, al corpo no, che nulla pave, a l'alma sì: deh! per lei prega, e dona battesmo a me ch' ogni mia colpa lave-. In queste voci languide risuona un non so che di flebile e soave ch' al cor gli scende, ed ogni sdegno ammorza, e gli occhi a lagrimar gli invoglia e sforza.

Poco quindi lontan nel sen del monte scaturia mormorando un picciol rio. Egli v'accorse e l'elmo empié nel fonte, e tornò mesto al grande ufficio e pio. Tremar sentì la man, mentre la fronte non conosciuta ancor, sciolse e scoprio. La vide, la conobbe; e restò senza e voce e moto. Ahi vista! ahi conoscenza!

Non morì già, ché sue virtuti accolse tutte in quel punto e in guardia al cor le mise, e premendo il suo affanno, a dar si volse vita con l'acqua a chi col ferro uccise. Mentre egli il suon de' sacri detti sciolse, 66 68

64

$$
\begin{aligned}
& \text { Al fin del fiero combate } \\
& \text { de Clorinda y de Tancredo, } \\
& \text { de quien fue clarín la noche, } \\
& \text { de quien fue testigo el cielo; } \\
& \text { ya desangrados los dos, } 5 \\
& \text { ya los dos faltos de aliento, } \\
& \text { con una punta el infausto, } \\
& \text { penetra el amado pecho. } \\
& \text { Viéndose ya la guerrera, } \\
& \text { reducida al punto extremo, }
\end{aligned}
$$
le dice: - «ya de tu parte amigo, está el vencimiento. Yo te perdono; perdón concede también; no al cuerpo, que nada teme; sí al alma; por ella interpone ruegos. Dame Baptismo, que lave con su gracia mis defectos; la que fue viva, rebelde, sierva se torne muriendo». El cielo en trance tan fuerte, le dictó tales acentos; llenos todos de Esperanza, de Fe, Caridad, y Celo. Un no sé qué de suave, y de piadoso hay en ellos, que el corazón del contrario, y los ojos vuelve tiernos.

Al pie del monte corría murmurando, un arroyuelo, allá, el semivivo parte, $y$ en sus ondas llena el yelmo. Vuelve, y en tanto que asiste al devoto oficio atento, sintió temblarle la mano al descubrir lo cubierto. Alzó la celada y vio, ¡oh miserable portento!, vio la Fénix de hermosura, vio la causa de su incendio Y a no importar el vivir

${ }^{54}$ Tasso (ed. 1991), Canto XII, octavas 64-70.

${ }^{55}$ Suárez de Figueroa (1629: 163-165; en edición digitalizada pp. 124-126). 
colei di gioia trasmutossi, e rise; $\mathrm{e}$ in atto di morir lieto e vivace, dir parea: $-« \mathrm{~S}$ 'apre il cielo; io vado in pace».

D'un bel pallore ha il bianco volto asperso, 69 come a' gigli sarian miste vïole:

e gli occhi al cielo affissa, e in lei converso sembra per la pietate il cielo e'1 sole; e la man nuda e fredda alzando verso il cavaliero, in vece di parole, gli dà pegno di pace. In questa forma passa la bella donna, e par che dorma.

Come l'alma gentile uscita ei vede, rallenta quel vigor ch' avea raccolto; e l'imperio di sé libero cede al duol già fatto impetüoso e stolto, ch'al cor si stringe, e, chiusa in breve sede la vita, empie di morte i sensi e '1 volto. Già simile a l'estinto il vivo langue al colore, al silenzio, a gli atti, al sangue. tanto, al sacro ministerio, al ver la infeliz tragedia, de dolor muriera luego. Recoge, pues, de su vida los espíritus postreros, y el corazón les da en guarda, porque cobre breve esfuerzo. Al pronunciar las palabras de su salud instrumento, luz de su sombra, la bella mostró semblante risueño. Tiene fijos en los orbes los eclipsados luceros, como que ya abierto mira el sitio del gozo eterno. Y la mano, en vez del habla, ofreciendo al caballero, tinta en un pálido hermoso, espira, en forma de sueño. Ausente ya el alma, el triste se precipita en el suelo, a su flaqueza rendido, y más a su sentimiento. Inmoble, tendido yace, tal, que al ponderar su aspecto, nadie diferencia o juzga cuál es el vivo o el muerto. 